\title{
Computer-Mediated Communication: Development of an Intranet for a University Academic Department
}

\author{
Oyenike Olufunmilayo Samantha Laoye* \\ Department of Computer Science \\ University of Ibadan \\ Ibadan, Nigeria
}

Received: March 1, 2005

Accepted: June 10, 2005

\begin{abstract}
The Intranet has been said to be one of the most important technological developments in Computer Communications. Whilst it is now a common, rapidly growing resource in the business world for the dissemination of information, it is yet to be fully explored in educational institutions. Intranets have an enormous potential to transform education in interesting and challenging ways as they offer an exciting approach for improving and facilitating innovative ways of supporting communication and also for accessing teaching and learning resources. This paper discusses the importance and usefulness of Computer-Mediated Communication in the enhancement of human communications and the focus is on the application of the Intranet (a form of ComputerMediated Communication) in the context of campus-based university education. This is illustrated by means of a case study and a realistic example i.e. the development of an Educational Intranet (CS.IntraNet) for the Department of Computer Science, University of Ibadan, Nigeria.
\end{abstract}

\section{INTRODUCTION}

Communication is important and vital to the human race. It is the only means through which information can be transferred, retrieved or shared. As human beings, we have engaged in face-to-face communication (i.e. oral form of communication) from the beginning of time on earth, and now, we have also developed various means to mediate this kind of communication in order to commune with one another from a distance or to leave a record of messages.

These have included the petroglyphs of the cave dwellers, the written word, the printing press and its resulting mass communications, the use of electric technology such as the Morse code and later, the miniaturization of such technology

*Email: nikybiggy@yahoo.co.uk into electronic devices- telephones, radio, television and also, the use of the computer. The reliance people once had on physically moving from one location to another in order to connect with other people or to retrieve information is being replaced by the ability to communicate electronically.

As all changes to the channels of human communication bring new dimensions and variables, communication technologies have brought about an additional dimension with the use of the computer as an interface.

The evolution of the spoken word now incorporates the computer as a transmission channel, retains the written word, and combines it with other telecommunication technologies to bring about another form of communication which is known as Computer-Mediated Communication (CMC).

The term, Computer-Mediated Communication (CMC), refers to any type of 


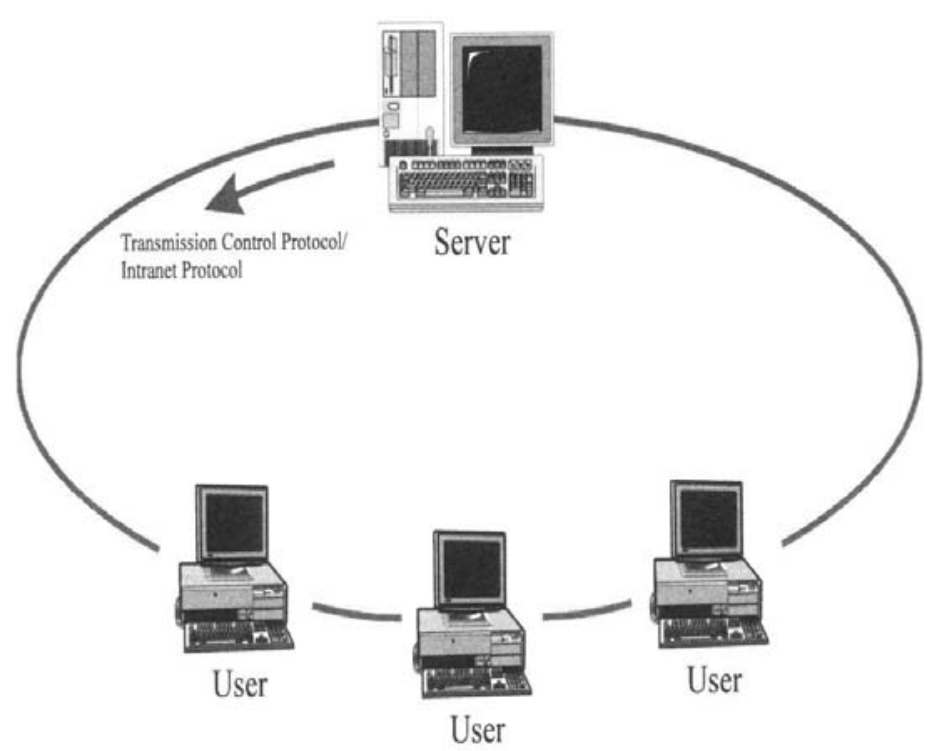

Figure 1. The Intranet Connection (diagram from: Hopkins [11]).

human communication that is electronically mediated [1]. This includes communication carried out by electronic mail, voice mail, chat mode on various systems, facsimile transmission, groupware interaction, the intranet, online bulletin boards, videoconferencing, multimedia, the Internet etc.

The intranet is one of the many forms of computer-mediated communication and its definition starts, of necessity, with the Internet, from which it originated.

If we define the Internet as the public network of networks that connects people and computers worldwide, intranets, in contrast, represent a single organisation's internal network and the applications on it [2].

Intranets are essentially a private, in-house, web-based network resource [3] and they are an increasingly familiar feature in large organisations that use web technology to deliver in-house access to IT resources and communication facilities

But intranets have not only brought changes and improvement to business organizations in which they are largely used but they are now one of the most useful applications in educational institutions as well.

By "Computer-Mediated Communication-Intranets in Education", we mean the use of the Intranet as a form of ComputerMediated Communication in education i.e. the deployment of Intranet-based technologies in an educational institution.

The purpose of this paper is to give an introduction to Intranets, show forth the effectiveness and significance of using a departmental intranet which will assemble useful educational information, organize it into logical systems, and deliver the information in an efficient manner.

\section{THE INTRANET}

According to Guengerich et al. [4], William Safire was probably the first person to use the term 'intranet' publicly in his New York Times column in 1994 but what exactly is an intranet? The intranet is a private computer network (Local Area Network) that serves many of the same functions of the Internet, internal to an organization [5]. It is also referred to as an ITC (Information Technology Communications) development that offers organisations an internal facility that is both a practical and increasingly familiar (through web-use) means for personnel to communicate with each other and access information from databases only limited by resources available to the organisation [2]. But simply put, an intranet 
is essentially an Internet contained within an organization. Some basic characteristics of an Intranet are:

- Contained. An Intranet typically is a local area network (LAN) or a Wide Area Network (WAN) within an organization.

- Shielded. An Intranet offers the "common language" of the Internet without the loss of privacy of the Internet.

- Gated. An Intranet can be connected via gateways to selected Internet content or access.

- Functional. An Intranet is a fully operational network for organizationwide communication, information, and interaction.

- Size. Intranets come in different sizes. In a small company, an intranet can be composed of only a handful of computers. In a medium-sized business, it may include dozens or hundreds of computers. And in a large corporation, there may be thousands of computers spread across the globe, all connected to a single intranet.

The Intranet is also an inexpensive yet powerful alternative to other forms of internal communications, including conventional computer setups as they complement or substitute most internal communications in use because they allow faster communication, wider distribution and greater efficiency than many printed and electronic media.

\section{a. History of the Intranet}

The Intranet has its roots embedded in the technology of the Internet. It is a network that uses the Internet's Transmission Control Protocol and the Internet Protocol (TCP/IP) for its underlying transport. Shortly after the web became popular, companies began to discover that these web protocols were not only useful for the Internet, with its worldwide reach, but also for a company's local area network (LAN). In other words, TCP/IP can be used on a LAN to create a private internet, a localized version of the World Wide Web (WWW) that only computers on the LAN can access. This became known as intranets, because they resemble the Internet but work within a single network rather than across the global network [9].

The practical use of intranets has only really developed since around 1995 and their application is being improved upon constantly as they are now commonplace within different organisations. Besides, the ease with which information can be shared, and with which people can communicate with one another will continue to drive the building of intranets as these internal webs are growing from an explosion in the use and understanding of the Internet technology from which they originated

\section{b. How the Intranet Works}

Intranets work in exactly the same way as Internet web servers; sharing 'the technological DNA of the Internet' [4]. That is they use the Internet standards of HTML (HyperText Markup Language), HTTP (HyperText Transfer Protocol) and TCP/IP (Transmission Control Protocol/Internet Protocol). For an intranet to function properly, all computers connected together in the network must speak and understand these language and protocols.

Driving the intranet is a network server that uses software known as a browser, usually Netscape Navigator or Microsoft Internet Explorer. It is the browser's job to contact the server, receive HTML pages, and then interpret and display those pages. When browsers are launched, they will visit a certain location by default. On an intranet, that location may be a departmental Web page or a company-wide Web page. This is the default page for accessing the intranet from any computer attached to the internal network. Also, by using hyperlinks to specific files or databases, requests for files are sent from anywhere on the network to the browser. The server accesses the file and sends back a copy of what it contains to the computer that asked for it.

It is the very simplicity of TCP/IP that makes intranets so easy to setup. Web browsers can be connected to virtually any information source, from Structured Query Language (SQL) databases to highly proprietary information systems. As Fuller and Pagan [6] stated, it is 'because the browser has evolved far beyond its original uses, it may well become the universal 
interface to all information resources in the future'.

Furthermore, Intranets often contain private or sensitive information that organisations do not necessarily want to share with the public at large; they are normally protected from external public access by means of a 'firewall'. A firewall is 'a system (software, hardware, or both) that enforces an access-control policy between two networks' [6]. Firewalls, then, are simply an artificial barrier that stops unwanted people, external to the organisation, from entering the local network of the intranet. In addition to unwanted users, firewalls can protect intranets from unwanted data and viruses.

\section{c. Why Use an Intranet?}

There are many factors which are tipping the scales toward the Intranet approach and this is because it offers many advantages to both the organisation and its personnel. Baines [7] notes the benefits intranets bring in terms of high productivity, improved communication and team working. The first and perhaps the most obvious advantage is access to electronic databases, documents, electronic manuals etc. that is available in a 'timely, accurate and convenient way'. Any information an organisation deems informative and useful can be stored in central databases to be extracted by browsers when needed without members having to leave their desks. Secondly, intranets encourage the integration of applications; such as wordprocessing with e-mail, and as such may be viewed as redefining the ways and possibilities in which computers can be used more efficiently. A third feature of intranets is that everyone with access to a computer terminal can obtain a wealth of information that by its electronic nature can be easily updated at regular intervals. A fourth advantage is the ease of use of the end user because of the very proximity of intranets to the Internet. Because intranet technology is based upon the user-friendly atmosphere of the World Wide Web (WWW) and familiarity with hyperlinks makes accessing information a mere click away, the system is easy to use and requires little or no training at all. It does not matter that users do not necessarily understand the intricacies of how the information got to their workstation; it is the ease of obtaining it that matters. A fifth advantage is one of the intranet's most obvious virtues - its ability to slash the need for paper. It saves reproduction costs of paper-based information e.g. handbooks, manuals, documents etc as they can be converted to electronic form for easy retrieval and constantly updated for almost nothing. Finally, as Hopkins [3] states it is the 'flexibility' of intranets that is the most exciting aspect of this technology.

\section{d. Intranet Use In Corporations}

With the enormous growth of the Internet, an increasing number of people in corporations use the Internet for communicating with the outside world, for gathering information, and for doing business. It did not take long for people to recognize that the components that worked so well on the Internet could be equally valuable internally and that is why intranets are becoming so popular in the business sector. They are an increasingly familiar feature in organisations and business corporations worldwide that use web technology to deliver in house access to IT resources and communication facilities.

Intranets are widely used internationally. For example, according to a survey done in the United States of America [4], it was found out that two-thirds of U.S. organizations 'either have an intranet installed or are actively considering installation of one' and in recent times, that number has greatly increased.

This is surely an endorsement that intranets offer the most innovative, costeffective way of freeing corporate information from the inaccessibility of expensive-to-maintain legacy systems, but, it is still an under-used resource in some countries especially Nigeria where only few companies make use of them.

A typical example of a corporate intranet within Nigeria is that of Maersk Nigeria Limited, a multi-national shipping firm- a subsidiary of Maersk Sealand International, which contains useful information, electronic manuals, training materials, forms and other documents used in handling different facets of their shipping business transactions. 


\section{INTRANETS IN EDUCATION}

The term "Intranet in Education" refers to the deployment of Intranet-based technologies in an educational institution such as a School/College/University [8]. Many universities adopted the Web early and have developed their own distinctive approach to graphic design, user interface design, and information architecture.

In most educational institutions, the use of the World Wide Web has evolved over the years from an informal collection of personal or group home pages into a semiorganized collection of sites listed in one or more master "home pages" or "front door" sites. Currently, most universities in the United States and United Kingdom have (or are in the process of creating) an intranet as University Computing has taken on a new role with the widespread popularity of the World Wide Web but the key determinant of the value of establishing an Intranet is an institution's information needs. It might not exactly be justifiable for every institution to deploy an Intranet. For example, a small school operating from a single location, may exchange local information more than adequately through non-electronic means (memos, meetings). It may use the Internet as a resource for gathering information, but probably doesn't need an Intranet (and the specific advantages it offers).

On the other hand, a University with multiple campuses in different locations and thousands of students could have the information needs that may benefit significantly from implementing its own Intranet. Educational Intranets, when properly implemented, truly offer the advantage of facilitating innovative ways of supporting students through exciting and interactive computer based learning and training.

\section{a. Advantages of an Educational Intranet}

There are several advantages in creating an educational Intranet:

- Ease-of-Use. With Intranet clients (browsers), a single front-end can be used to access all internal and external resources; users don't need to learn multiple software packages.
- Cost-Effectiveness. Intranet tools are inexpensive in initial purchase and deployment. A variety of client and servers-side software is almost free for academic or noncommercial use. The Intranet's platform-independence usually eliminates the need to create different versions of the same application. Setting-up an Intranet can also save resources. For example, office and phone directories can be made available in an electronic form on the Intranet, instead of printing them.

- Asynchronous Global Information. Information can be accessed any time and anywhere, thus overcoming the time and space dependent limitations.

- Universal Communication. Intranets provide a more efficient communication link as it suggests a better mode of communication over typical oral and written forms of communication. With proper authorization, an individual on an Intranet can interact with any other individual within the internal network and beyond with outside world.

- Publishing. Through multimedia support, the WWW technology offers a complete environment for publishing information in dynamic form. Hypermedia makes this information reusable by instant referencing.

- Flexibility. Even though an Intranet uses Internet-based technologies, it doesn't need to conform to a certain design and engineering considerations that are sometimes expected (and even required) on the Internet. The power of the Internet can be applied with flexibility to individual institutional requirements.

- Maintainability and Efficiency. An Intranet gathers and disseminates necessary information in a timely manner. Also by setting-up and maintaining an internal WWW site, one can be assured of up-to-date information.

- Security. Protecting information, even within an educational network, 
is critical. Intranets are protected by a firewall, a network configuration usually created by hardware and software that forms a boundary between networked computers within the firewall from those outside the firewall. For Internet access, Intranets rely on proxy servers, a special server that typically runs in conjunction with a firewall and allows access to the Internet from within the firewall. This enables institutions to make only necessary information available to the outside world (based on means of privileged access, such as username/ password-based authentication) thereby avoiding the problems of security breach, server overload and access of illegal information.

- Learning. The Intranet technology offers several approaches to facilitating and providing the necessary personalized help resources that can be made available to students. By deploying Intranets in universities, different kinds of resources and information (lecture notes, exercises, quizzes, syllabi, etc.) can be made available to enrich the students' academic life. Setting-up an environment on a smaller scale (Intranet), also gives the students an opportunity to develop their skills and protocol to communicate on a larger scale (Internet).

b. Existing Educational Intranet Applications

Examples of various existing educational applications of the intranet are:

1. University of Teeside, United Kingdom, under the guidance and inspiration of Philip Barker, a longtime advocate for the integration of ITC (Information Technology Communications) into education, built and developed the use of intranets. Within the university, intranet facilities are available in 'all staff offices, lecture theatres, laboratories, libraries and most other buildings' [16].

2. At the University of Saskatchewan, Canada, the Intelligent Intranet Helpdesk is being currently employed to support peer-help among students in the CMPT 100 Introductory Computer Science course for non-majors. The Intelligent Intranet Peer Help Desk provides an integration and application of previously developed ARIES Lab tools within the university, for peer help to university teaching. One of its components, CPR, provides a subject-oriented discussion forum and FAQ-list providing students with electronic help. Another component, PHelpS, suggests an appropriate peer to provide human help. In both cases it is peer help, since the help originates from students themselves [9].

3. The University of Lancashire, United Kingdom has implemented the teaching and learning of computer skills via an intranetbased course, a non-majorable first year University Computing course (COM120) that provides novice users with fundamental computer skills.

4. Produced by the University of British Columbia, Web Course Tools -"WebCT is a tool that facilitates the creation of sophisticated World Wide Webbased educational environments by non-technical users. It can be used to create entire on-line courses, or to simply publish materials that supplement existing courses. WebCT also provides a conferencing system, on-line chat, student progress tracking, group project organization, student selfevaluation, grade maintenance and distribution, access control, navigation tools, auto-marked quizzes, electronic mail, automatic index generation, course calendar, student homepages, course content searches." 


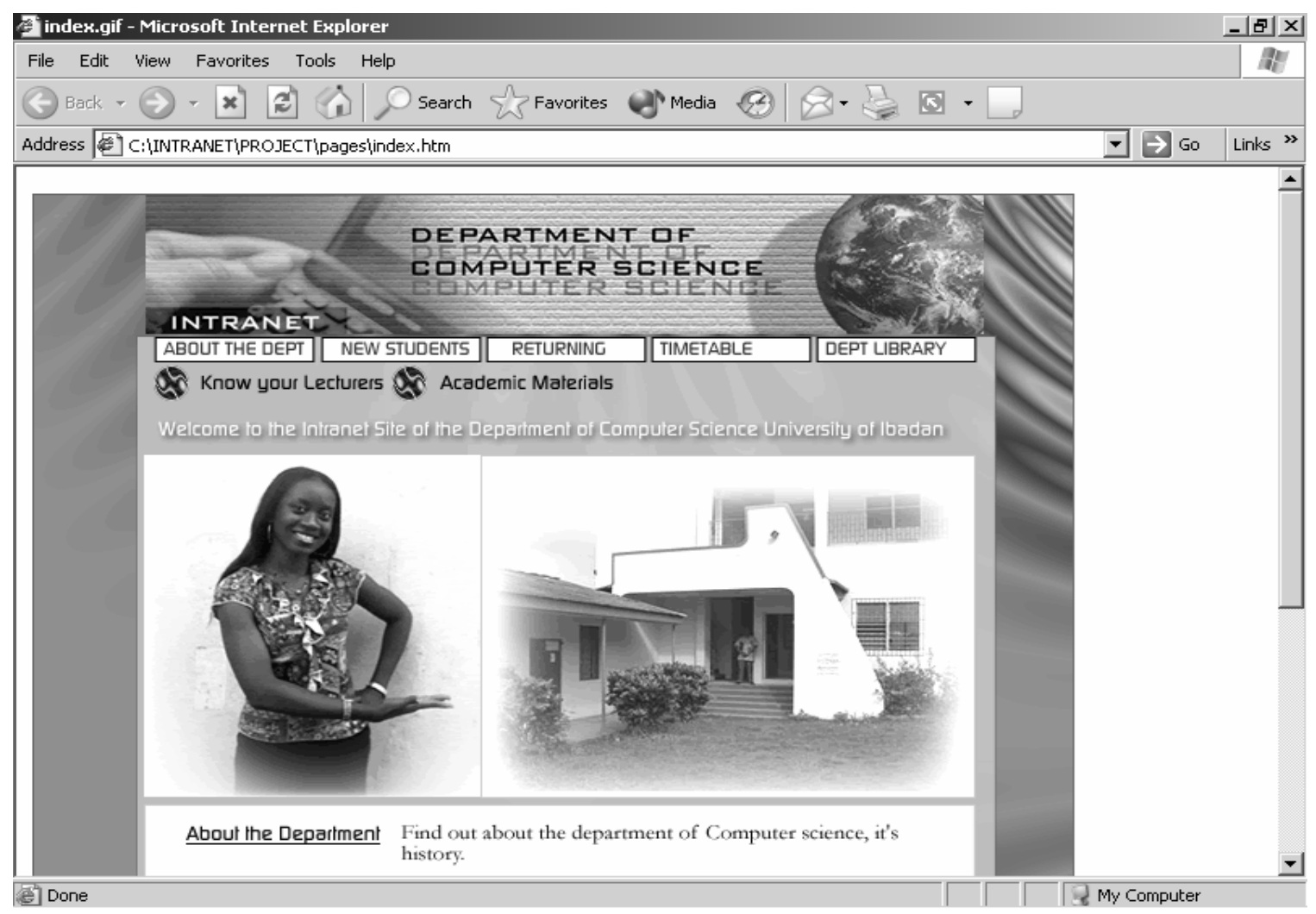

Figure 2. The Home Page of the CS.IntraNet at the University of Ibadan.

\section{THE DEPARTMENTAL INTRANET -CS.IntraNet}

Communication is one vital point within a University environment because every activity that takes place there is based on it and to evaluate this fact, a study was carried out on the existing communication system within the Department of Computer Science, University of Ibadan, Nigeria, and it was observed that the students require basic information regularly on activities and happenings related to their course of study. These can be presented in the form of queries such as:

- When are lectures taking place?

- Which and How many courses are to be taken per semester?

- How many units are required to be passed per session?

- Which lecturer is taking a particular course?

- Which books are recommended for a course?
- Are these books available in the departmental library?

And prior to these queries being answered, there has to be some form of communication system by which the required information is passed across to the students.

It was observed that the existing communication system in use is a manual system i.e. the means of communication within the department is limited to only oral and written forms of communication in terms of announcements made in the lecture rooms, notes pasted on the departmental notice boards and face-to-face interaction (the relaying of messages from one person to another).

From this system evaluation, it was concluded that the existing system is inadequate as a number of problems such as inaccuracy and loss of information are inevitable; therefore, the need for a new system, which will enhance the means of relaying information, arises due to these shortcomings of the existing system. This led to the exploration of Computer-Mediated 


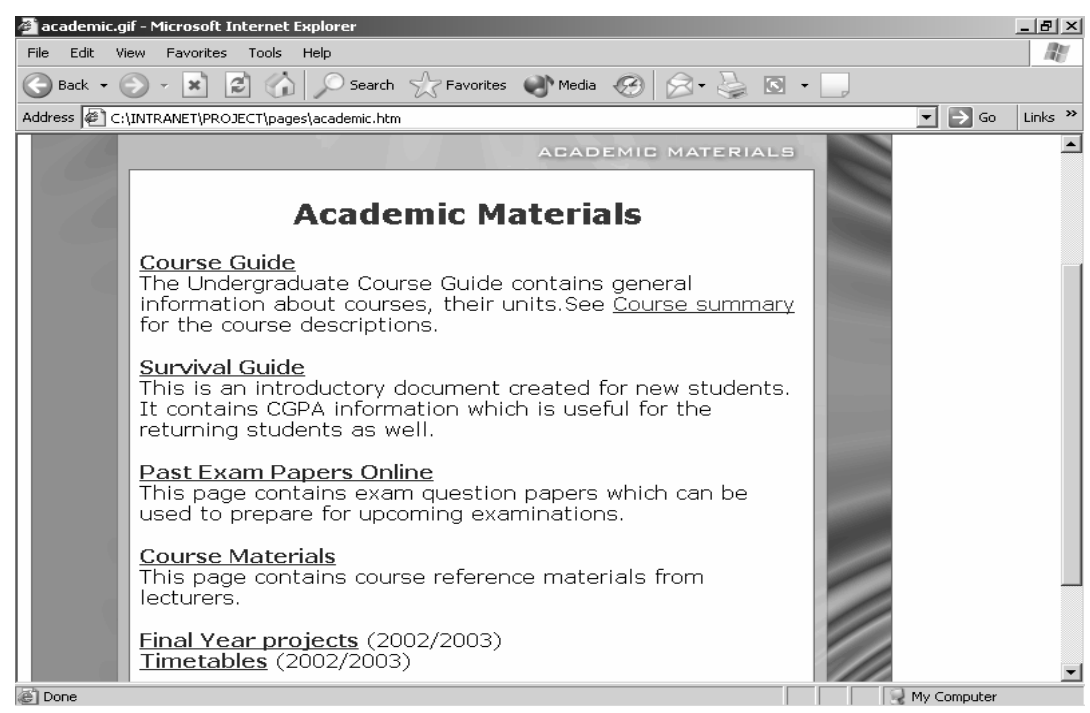

Figure 3. Academic Materials Page of the CS.IntraNet.

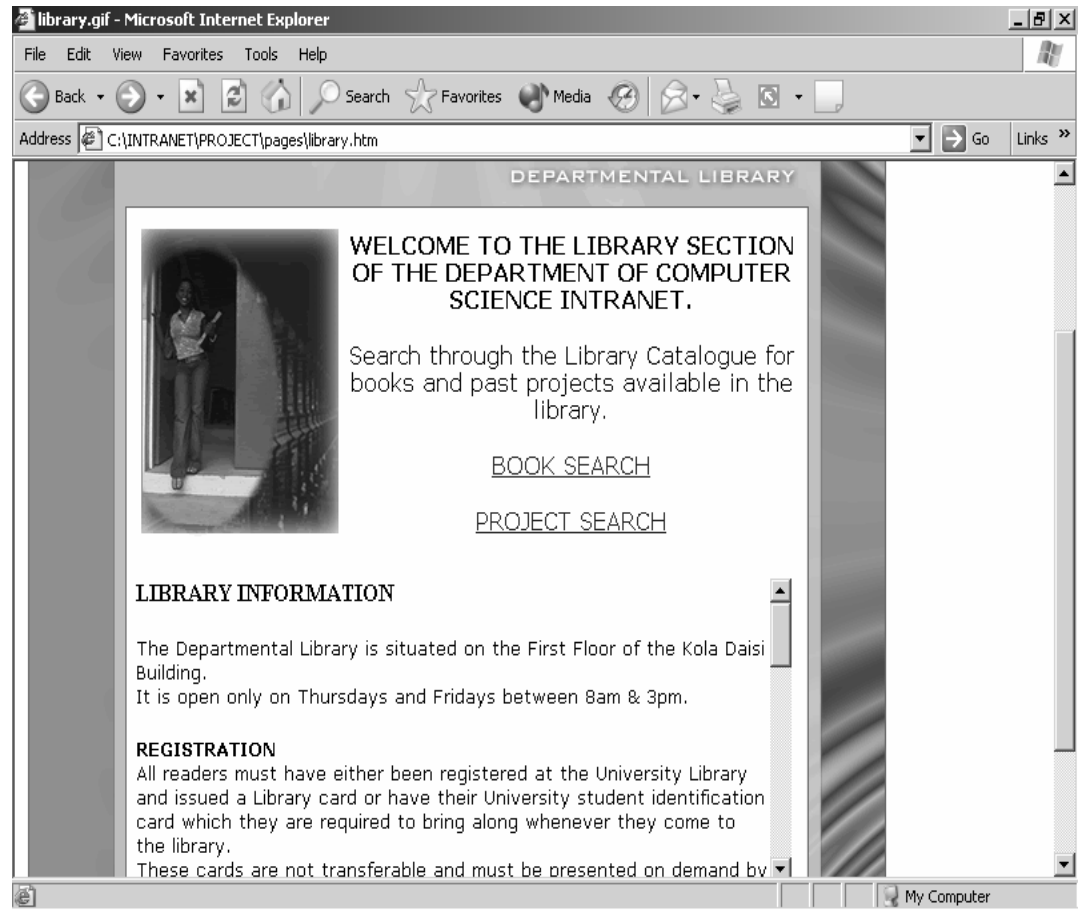

Figure 4. The Departmental Library Page.

Communication as a means of communication by the development of the departmental intranet-CS.IntraNet. This new system suggests a new and better way of communicating, by computerizing the existing system, which will solve or totally eradicate most of its observed problems

CS.IntraNet is an educational Intranet that can be used as a communication tool for providing meaningful and useful information of high academic significance to the undergraduate students of the department of computer science, University of Ibadan, Nigeria. It comprises of a set of internal web pages containing relevant academic information for students such as course syllabi and content, information about the department, project 


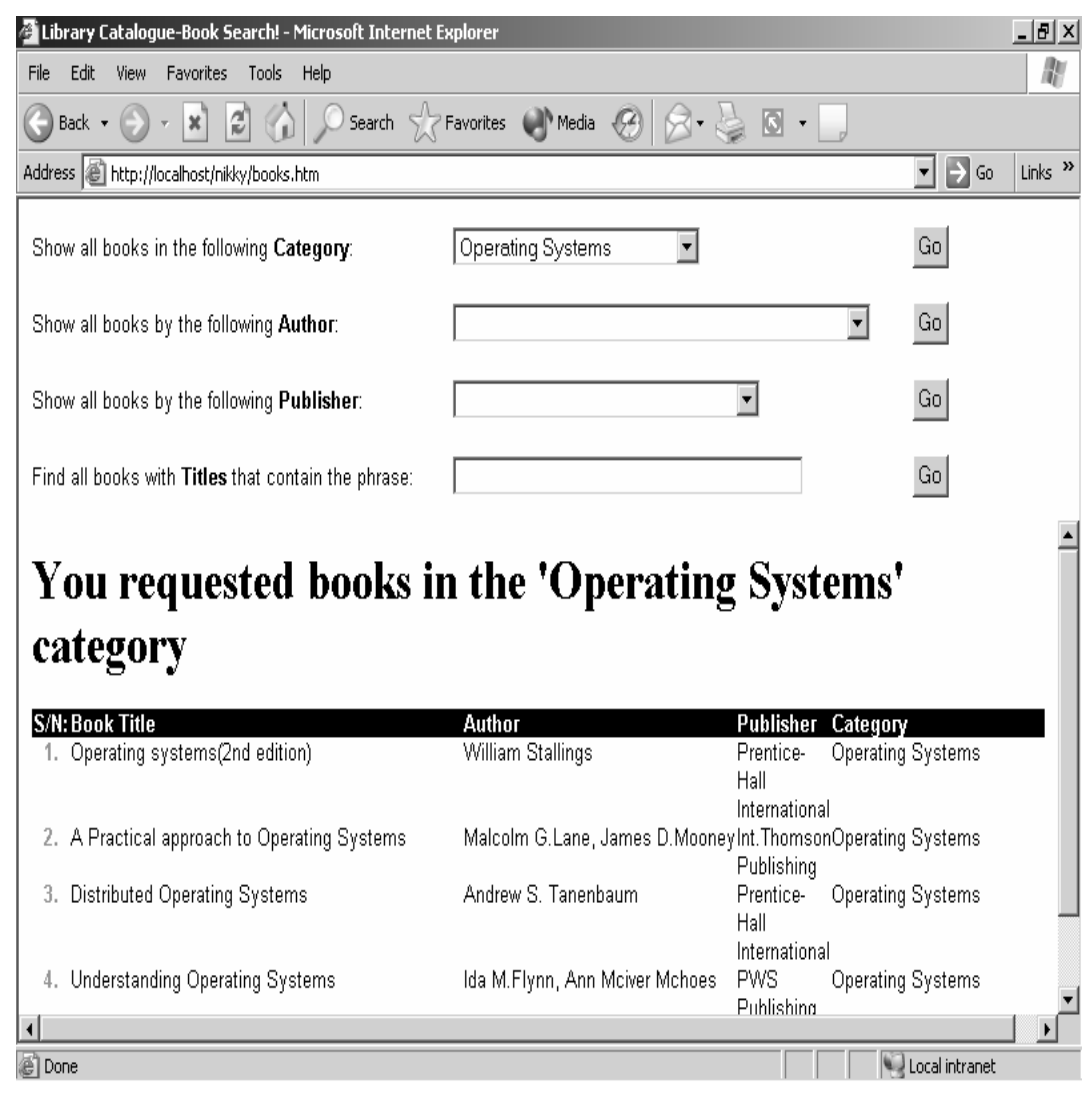

Figure 5. The Book Search Page of the Library Catalogue

issues for final year students, academic materials, lecturers' online profiles, past exam question papers etc. Some of the pages within the CS.IntraNet are:

\section{a. Home Page}

This is the first page to be loaded into the browser when its URL (Uniform Resource Locator) is typed into the address bar. The Home Page can be accessed from any page in the site. Figure 2 shows the screenshot of the Home Page of the CS.IntraNet. It consists of a menu bar - five major buttons labeled About the Department, New Students, Returning Students, Time Table, Dept. Library and two minor buttons labeled Know Your Lecturers, and Academic Materials. These buttons are used to navigate to the other pages within the site. Hyperlinks of these buttons are also included within the second frame of the page as well, each link has descriptive remarks which inform the site visitor of the page's contents and these can also be used to navigate through the site.

The home page also consists of images-one shows a static image of the author gesturing towards a picture of her department. There is a rollover action when the mouse is placed on any of the five major buttons, i.e. the picture of the department changes to a different picture when the pointer moves across each button. The rollovers actually consists of two images: the primary image (the image displayed when the page first loads) and a secondary image (the image that appears when the pointer moves over the primary image).

\section{b. Academic Materials Page}

The academic materials page is one of the most useful pages for the students. It provides students with direct, continuous and timely access to educational materials such as course reference materials, past examination question papers, the electronic 
version of the course description guide, lecture time tables and other course-related documents. Figure 3 shows a screenshot of the academic materials page.

\section{c. The Departmental Library Page}

The most interactive part of the CS.IntraNet is the Departmental Library page which has a search engine called the Library Catalogue. It is an online catalogue of the department's library which offers the systematic list of books, past projects and other reference materials available in the departmental library that can be used for study and reference purposes by students and lecturers alike.

The catalogue is a set of dynamic databasebacked web pages which were designed using ASP (Active Server Pages) server technology with VBScript language and HTML (Hyper Text Markup Language).

HTML (Hyper Text Mark-Up Language) was used in the designing of the intranet's web pages and it was also used alongside VBScript(Visual Basic Script Language), ASP (Active Server Pages) to develop the library catalogue. Microsoft Access was the database software used in creating the database for the library books and projects. The Web browser used, as the client-side application is Microsoft Internet Explorer while the Server-side application is a database created in Microsoft Access that runs alongside a Web server, Microsoft's Internet Information Server.

\section{CONCLUSION}

Like the breakthrough from Oral Communication to Written Communication that preceded it, Computer-Mediated Communication is becoming a part of our overall human communication- not as a substitute for, but as a supplement to, faceto-face interaction.

This paper has been able to discuss the effectiveness of the Intranet as a CMC tool within an educational institution. The techniques involved in using this approach for teaching, learning and communication within a university setting have been illustrated by means of a case study (the development of an informative, educational intranet -"CS.IntraNet" - for the Department of Computer Science, University of Ibadan, Nigeria).

But some people might still inquire: Is there really a measurable educational benefit from Intranets? From the detailed examination of intranets in this paper, the answer is an irrefutable yes. Intranets do offer phenomenal potential to the development of communication and learning in the millennium as the establishment of an Intranet within an educational institution can create a - long-term, cost-effective, efficient, information-accurate, and fruitful - teaching and learning environment

It has been noted, however, that due to the lack of information and insight on the intranet, its technology is yet to be explored in the educational sectors of Nigeria and other countries. This was the major reason why this study was taken up to create an interest in the educational communities, motivate them to establish Intranets in their institutions and make them realize that the Intranet technology tends to offer a highly flexible resource capable of contributing usefully to many different visions of what university education is (or ought to be) about. Educational intranets can be an exciting, innovative - and if used to their full potential - a fully interactive medium of communication.

\section{AUTHOR'S NOTE}

This research was completed in partial fulfillment of the requirements for the award of the Bachelor of Science Honors Degree (BSc.Hons) in Computer Science at the University of Ibadan, Nigeria in March 2004.

\section{ACKNOWLEDGEMENTS}

I would like to deeply appreciate Dr. B.A Oluwade for his support, guidance and great belief in me. It was your encouragement that brought me this far, thank you so much. I would also like to thank my Supervisor, Mr. S.O Akinola for his patience and advice during the course of this research.

To my parents, Mr. and Mrs. Shola Laoye, I say a big thank you for your constant love and support.

And finally, indeed, I owe the complete success of this work to no one else but God Almighty. 


\section{REFERENCES}

1. Marold, Kathryn A and Gwynne Larsen, Beyond the Internet: Using Computers to Communicate (IThomson Learning, London, 1996).

2. Brown, David, "Intranets: What are they and is there a place for them in Education?"

http://www.cbltwork.soton.ac.uk/bown/fo un/

3. Hopkins, Bryan, How to Design and Post Information on the Corporate Intranet (Gower Publishing Co., Aldershot, Hampshire, UK, 1997).

4. Guengerich, Steve, Douglas Graham, Mitra Miller, Skipper McDonald, Building the Corporate Intranet (Wiley, New York, 1996).

5. Kantor, Peter L (web source) History/ Protocols/Networks at http://academ. hvcc.edu/ kantopet/index.php?pg=netw orks\&tp=protocols\&sb=networks

6. Fuller, Scott. and Kevin Pagan, Intranet Firewalls (Ventana Press, Chapel Hill, North Carolina, USA, 1996).

7. Baines, A., "Intranets", Work Study, Vol. 45, no 5, pp.5-7 (1996).

8. Kamthan, Pankaj, "Intranets in Education," http://tech.irt.org/articles/ Intranets in Education.htm (1998)

9. Greer, Jim, Gordon McCalla, John Cooke, Jason Collins, Vive Kumar, Andrew Bishop, and Julita Vassileva, The Intelligent Helpdesk: Supporting Peer-Help in a University Course" ARIES Laboratory, Department of Computer Science, University of Saskatchewan, Saskatoon, S7N 5A9 CANADA,

http://julita.usask.ca/Texte/Jim-html

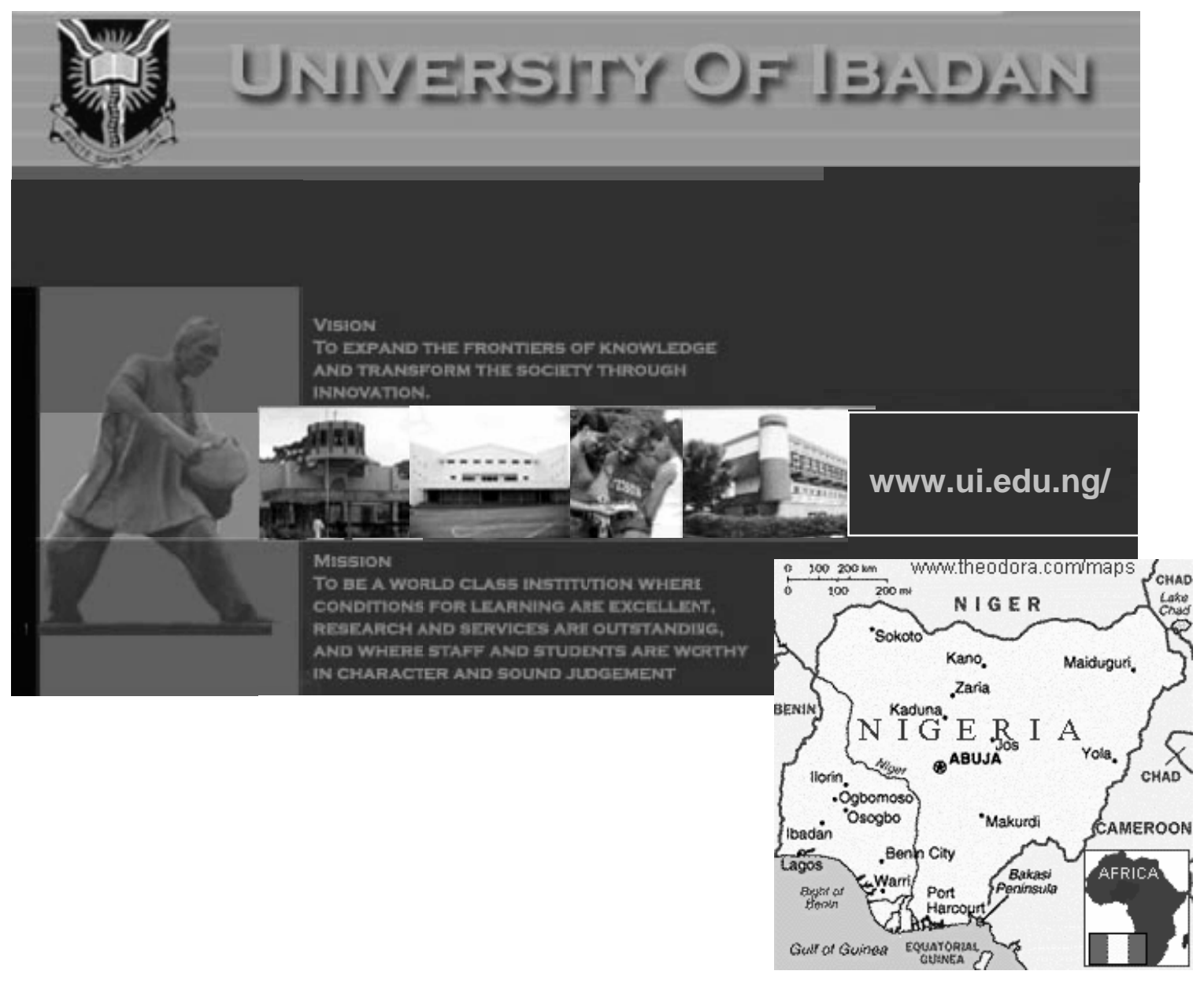




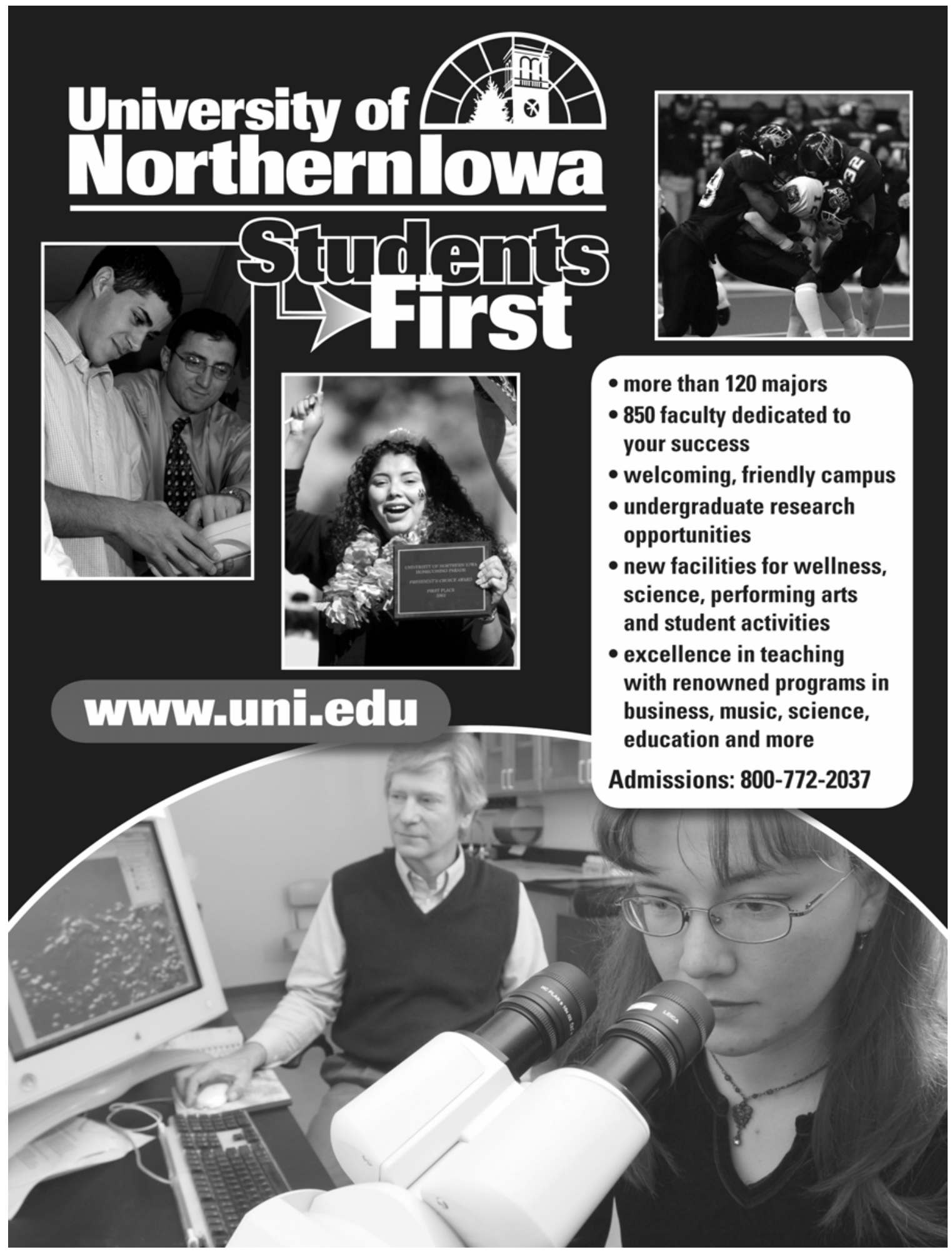

